\title{
Study the impact of different preparation methods on the structural and dielectric properties of nickel-zinc ferrite
}

\author{
Marwa Taha ${ }^{1 *}$, Tahseen H. Mubarak ${ }^{2}$, Abdul Samee F. Abdul Aziz ${ }^{1}$ \\ ${ }^{1}$ Department of physics, College of Sciences, University of Tikrit, Iraq \\ ${ }^{2}$ Department of physics, College of Sciences, University of Diyala, Iraq
}

*Corresponding author: marwataha026@gmail.com

(C) The Author

2021.

Published by

ARDA.

\begin{abstract}
In the current study, nickel-zinc ferrite nanoparticles Ni (1-x) ZnxFe2O4 ( $\mathrm{X}=0$, $0.25,0.50,0.75,1)$ have been arranged by sol-gel auto combustion and common chemical precipitation methods, The samples were described by $\mathrm{x}$-ray (XRD) deflection, Fourier converts Infrared Spectroscopy (FTIR), dielectric perpetual and dielectric loss element. the XRD analysis confirms the cubic lone phase spinel configuration for all the synthesized materials. Average crystalline size is estimated of the (311) peaks of the x-ray diffractogram using Scherrer's formulation institute in the range 38.90 to $37.71 \mathrm{~nm}$ for sol-gel auto burning method and from 18.61 to $23.41 \mathrm{~nm}$ for co-precipitation method.

The Fourier transform infrared spectroscopy was studied so as to assert the construction of the spinel phase and to recognize the kind of carbon remaining in the samples. The dielectric fixed and the dielectric loss factor were measured in the range between $50 \mathrm{~Hz}-3 \mathrm{MHz}$ at room temperature were located to be reduced with a rise in regularity.
\end{abstract}

Keywords: Nickel-Zinc ferrite nanoparticles, X-ray, Scherrer's formulation, Infrared Spectroscopy

\section{Introduction}

Ferrites are substances of significant benefit due to their unusual insulator, optical, and magnetic properties, making both of them scientifically and technologically attractive [1]. The use of Ni-Zn ferrite in electromagnetic interfaces known as EMIs is more commercially available for use on hard drives, laptops and other product electronics. Ferrites are high resistivity, which is considered one of the applications of microwave [2,3]. Since their height is favored Electrical strength, mechanical hardness, chemical stability and cost-effectiveness [ 4-5]. These are also helpful prevent and remove audio distortion from radio frequency devices. Ferrites of NickelZinc are a favor magnetic technological materials different mobile devices uses [6]. The basic behavior of thermal activation of the $\mathrm{Ni}-\mathrm{Zn}$ ferrite cycle Electron jumping from cation to cation and not [7] Due to shipping carriers' development. Zinc is considered to be a deciding factor the compositional difference in ferrite properties [8]. the ferrites were caused by zinc variation focus. The movement of ions in the metal spinel lattice positions tetrahedral and octahedral zinc inclusion shall be responsible for the amendment of the attributes to ferrite. Nickel - Zinc are well-known strong tetrahedral and octahedral websites preference, $\mathrm{So} \mathrm{Ni}-\mathrm{Fe}_{2} \mathrm{O}_{4}$ a reverse ferrite type and respectively $\mathrm{Zn}-\mathrm{Fe}_{2} \mathrm{O}_{4}$ a ferrite type [9]. Nano-size, however, Nickel-and Zinc-ferrite are well-known for being a spinal mix structures $[10,11]$.

In this study, we reported the synthesis with chemical co-precipitation and sol-gel combustion method of nanocrystalline -sized mixed ferrite, namely $\mathrm{Ni}_{(1-\mathrm{x})} \mathrm{ZnxFe}_{2} \mathrm{O}_{4}$. Analysis of the structure was performed using (XRD).

This work is licensed under a Creative Commons Attribution License (https://creativecommons.org/licenses/by/4.0/) that allows others to share and adapt the material for any purpose (even commercially), in any medium with an acknowledgement of the work's authorship and initial publication in this journal. 
The insulating properties of the synthesized sample were measured using vibration sample, and discussed in detail.

\section{Experimental details}

\subsection{Materials}

All chemicals including $\mathrm{Ni}\left(\mathrm{NO}_{3}\right)_{3} .6\left(\mathrm{H}_{2} \mathrm{O}\right), \mathrm{Zn}\left(\mathrm{NO}_{3}\right)_{2} .6 \mathrm{H}_{2} \mathrm{O}, \mathrm{Fe}\left(\mathrm{NO}_{3}\right)_{3} .9 \mathrm{H}_{2} \mathrm{O},\left(\mathrm{C}_{6} \mathrm{H}_{8} \mathrm{O}_{7}\right)$, and $\mathrm{NaOH}$ were purchased from lndia and as received, without further purification.

\subsection{Synthesis}

In the present work $\mathrm{Ni}_{(1-\mathrm{x})} \mathrm{Zn}_{\mathrm{x}} \mathrm{Fe}_{2} \mathrm{O}_{4}$ where $\mathrm{X}=0,0.25,0.50,0.75$ and 1 were prepared using two different methods:

- Sol-gel: amounts of $\mathrm{Ni}\left(\mathrm{NO}_{3}\right)_{3} .6\left(\mathrm{H}_{2} \mathrm{O}\right), \mathrm{Zn}\left(\mathrm{NO}_{3}\right)_{2} .6 \mathrm{H}_{2} \mathrm{O}$, and $\mathrm{Fe}\left(\mathrm{NO}_{3}\right)_{3} .9 \mathrm{H}_{2} \mathrm{O}$ having molar ratio of 1:2 was dissolved in $(100 \mathrm{ml})$ of distilled water separately, mix the ingredients using the magnetic stirrer for half an hour until complete dissolution. Then add the ammonia solution in the form of drops to the mixture solution until a solution is obtained with its acidic function $(\mathrm{PH}=7)$ is balanced and continued Mixing at room temperature. after that we start to heat the solution, where the temperature of the magnetic stirrer is raised gradually and fixed at $\left(95 \mathrm{C}^{\circ}\right)$, after a period of time, the gases begin to rise and leave the reaction while continuing to move the solution until we get the gel shape. After about half an hour, the mixture begins ignited to form xerogel, after which the heat element is extinguished and the material is left to cool. The resulting powder is calcined at a temperature of $\left(700 \mathrm{C}^{\circ}\right)$ for two hours.

- Co-precipitation method: Nickel-nitrate, zinc-nitrate and iron-nitrate are dissolved in a 2: 1 ratio in (200 $\mathrm{ml})$ of distilled water and using stirrer magnetic at a temperature of $\left(60 \mathrm{C}^{\circ}\right)$ for a period of half an hour. Sodium hydroxide solution $\mathrm{NaOH}$ is added to the solution of the metal mixture in the form of drops while continuing to stir and keep the temperature constant at $\left(60 \mathrm{C}^{\circ}\right)$ where a clear $\mathrm{pH}$ of 12 is formed. The mixture is washed several times with distilled water to get rid of the insoluble nitrates. The mixture is dried at a temperature $\left(100 \mathrm{C}^{\circ}\right)$, for a completely moisture-free mixture. The resulting powder is dried at $700^{\circ} \mathrm{C}$ for two hours.

\subsection{Characterization}

The composition of the annealed samples was analyzed with the use of an $\mathrm{x}$-ray diffractometer to record powder diffraction spectra (Shimadzu XRD-6000) with $\mathrm{Cu} \mathrm{K} \alpha_{1}$ radiation $(\lambda=1.5405 \AA$ ). Spectroscopic analysis of the Forms is shown using a Shimadzu company infrared spectrophotometer. For the $400-4000 \mathrm{~cm}^{-1}$ wave number, transmission rates were measured. The dielectric studies for the pelletized samples were performed with LCRmeter (GWINSTEK, model $8105 \mathrm{G}$ ) in the range $50 \mathrm{HZ}$ to $3 \mathrm{MHz}$.

\section{Results and Discussions}

\subsection{XRD Analysis}

The XRD pattern for the forms $\mathrm{Ni}_{(1-\mathrm{x})} \mathrm{Zn}_{\mathrm{X}} \mathrm{Fe}_{2} \mathrm{O}_{4}$ for $(\mathrm{X}=0$, 0.25, 0.50, 0.75, 1) Figure $(1,2)$. shows seven peaks within the range $\left(\theta=10^{\circ}-80^{\circ}\right)$. peaks that refer to crystalline surfaces $(220,311,222,400,422,511,440)$ and that return to the ratio $\mathrm{x}=0,1$ they are identical to the standard numbered card (ICDD-054-0964) and the peaks related to the crystalline surfaces $(022,113,004,224,333,044)$ and for the ratios $X=0.25,0.50,0.75$, it was found to be identical to the standard numbered card (ICDD-052-0277). these peaks indicate the nature of the crystal structure of ferrite powders. The (XRD) spectrum shows that the phases formed are spinel phases despite different zinc concentration ratios. The single phase in the XRD measurement results may be due to characteristic preparation methods or to the purity of the raw materials used to prepare the samples [12]. Figure $(1,2)$ shows that the formed phase is the spinel phase of all samples and the face centered cubic (FCC) and no other phases are visible. 


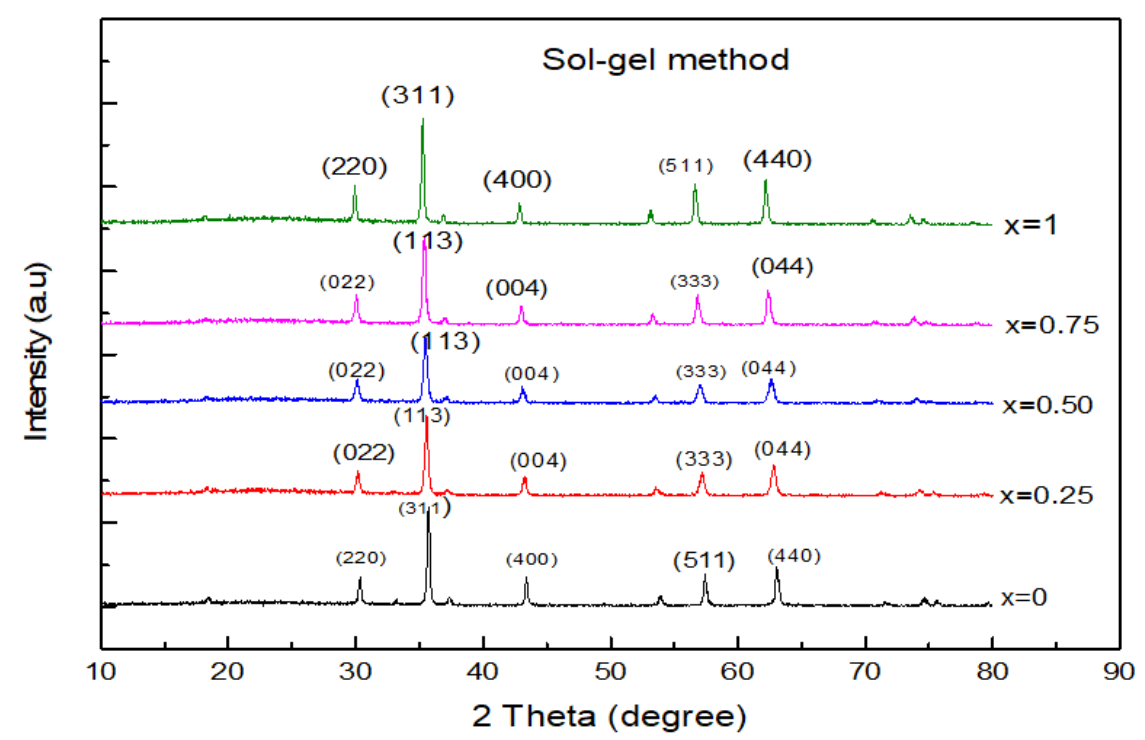

Figure 1. XRD of forms arranged by sol-gel method

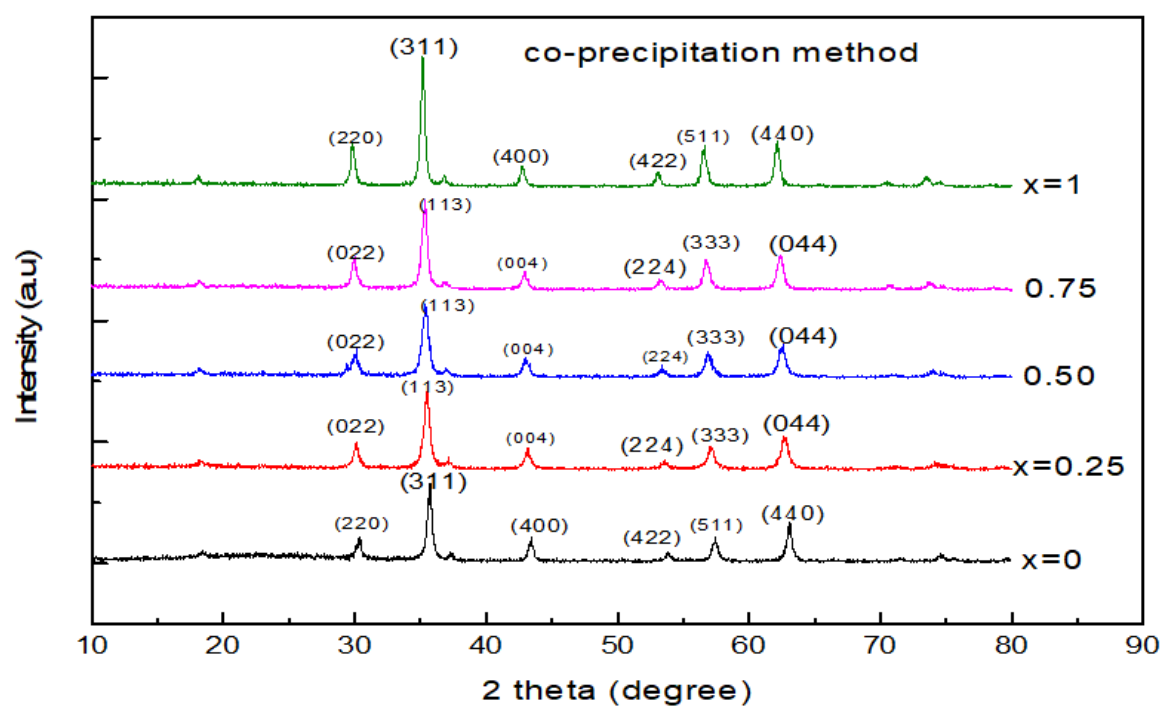

Figure 2. XRD of forms prepared by common chemical precipitation method

The calculated constant "a" of the lattice is rise from $8.327 \AA$ to $8.450 \AA$ with an increase in zinc concentration as shown in list 1 . The lattice constant depends on the ionic radius of $\mathrm{Zn}^{2+}(0.82 \AA)$ ions, the difference in (a) with zinc concentration can be described is higher than that of $\mathrm{Ni}^{2+}(0.78 \AA)$ [13].

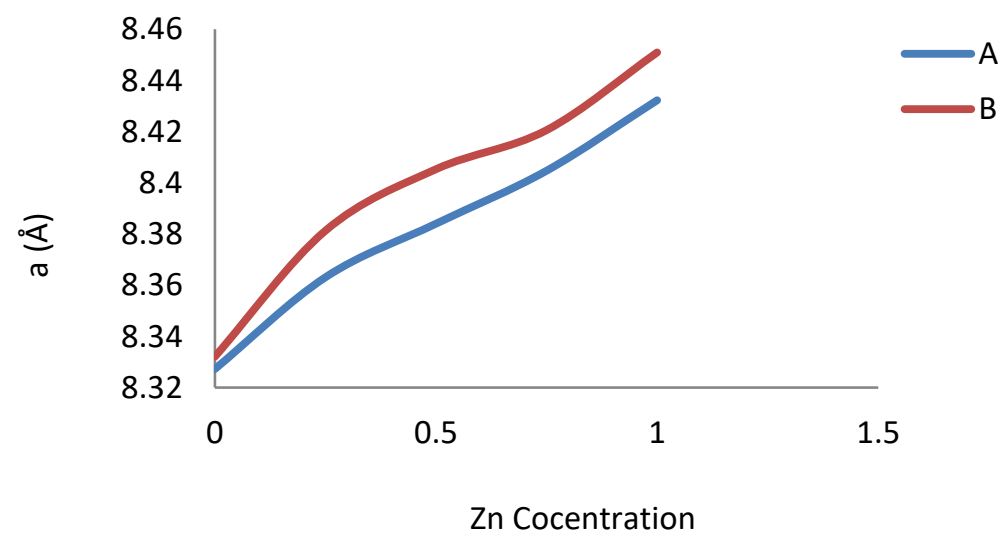

Figure 3. The lattice constant changes with the zinc focus for samples A, B prepared by sol-gel combustion and Common chemical precipitation methods respectively 
Fig. 4. shows that the crystalline size decreases with a plus zinc content. Thus, the existence of zinc hinders the growth of the crystal. The surface temperature affects the content of molecules at the crystal and thus the crystal grows. The structure $\left(\mathrm{Zn}-\mathrm{Fe}_{2} \mathrm{O}_{4}\right)$ is more exothermic compared to the structure $\left(\mathrm{Ni} \mathrm{Fe}_{2} \mathrm{O}_{4^{-}}\right)$and this leads to that the surface temperature of the crystal rise with an increase in the content of zinc and this leads to a reduction in the concentration of molecules at the superficial of the crystal and thus the grains growth is obstructed. The difference in crystalline size may be due to the difference in the preparation conditions used [14].

Table 1. Structural parameters of $\mathrm{Ni}(1-\mathrm{x}) \mathrm{ZnxFe} 2 \mathrm{O} 4$ where: A1 ,A2, A3,A4,A5 prepared by sol-gel method for ratios $0,0.50,1$ respectively and $\mathrm{B} 1, \mathrm{~B} 2, \mathrm{~B} 3, \mathrm{~B} 4, \mathrm{~B} 5$ prepared by Co-precipitation method for $0,0.25,0.50,0.75$,

1 respectively

\begin{tabular}{c|c|c}
\hline \multicolumn{1}{c}{ Ni Zn-ferrite for (311) } & lattice constant. & $\begin{array}{c}\text { Crystalline } \\
\text { Size }\end{array}$ \\
\hline Preparation method & $\mathrm{a}(\mathrm{A})$ & $\mathrm{D}(\mathrm{nm})$ \\
\hline $\mathbf{A}_{\mathbf{1}}$ & 8.327 & 38.897 \\
\hline $\mathbf{A}_{\mathbf{2}}$ & 8.363 & 30.165 \\
\hline $\mathbf{A}_{\mathbf{3}}$ & 8.384 & 24.355 \\
\hline $\mathbf{A}_{\mathbf{4}}$ & 8.404 & 29.159 \\
\hline $\mathbf{A}_{\mathbf{5}}$ & 8.432 & 37.705 \\
\hline $\mathbf{B}_{\mathbf{1}}$ & 8.332 & 18.611 \\
\hline $\mathbf{B}_{\mathbf{2}}$ & 8.381 & 15.987 \\
\hline $\mathbf{B}_{\mathbf{3}}$ & 8.405 & 14.503 \\
\hline $\mathbf{B}_{\mathbf{4}}$ & 8.420 & 17.407 \\
\hline $\mathbf{B}_{\mathbf{5}}$ & 8.450 & 23.412 \\
\hline
\end{tabular}

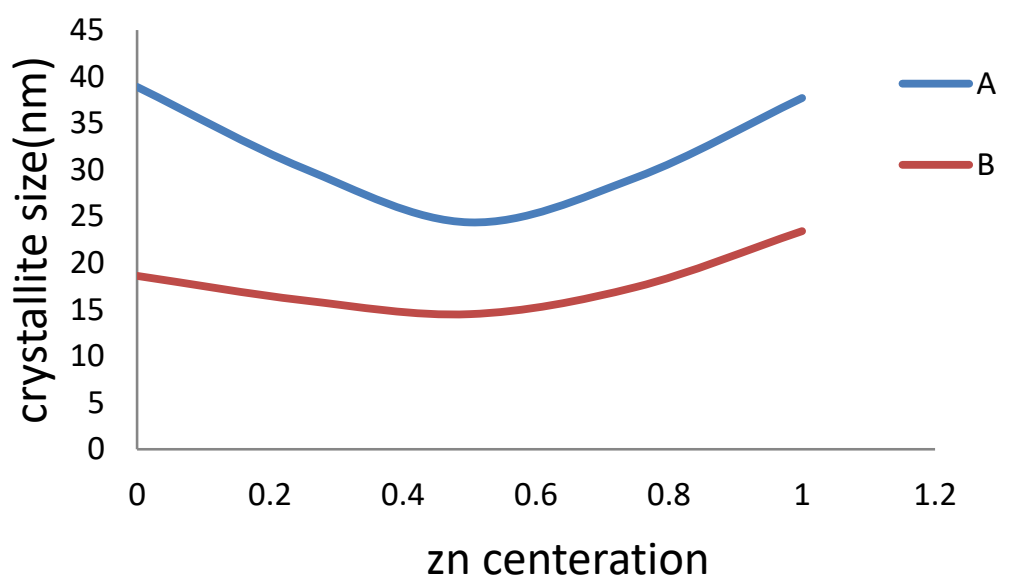

Figure 4. Variation of the average crystallize size with $\mathrm{Zn}$ concentration for samples A, B ready by sol-gel combustion and Common chemical precipitation methods respectively

\subsection{Fourier transform infrared (FT-IR) spectroscopy analysis}

FTIR analyzes are used to statement the formation of the spinel phase and to understand the nature of the carbon remaining in the samples. Figure 5. shows the types of IR spectrum of the samples intended by the Sol gel method. The range of vibrations of the ions in the crystal lattice is set between $\left(500 \mathrm{~cm}^{-1}-800 \mathrm{~cm}^{-1}\right)$ and it represents the band $v_{1}$ that is set to $\left(\mathrm{Fe}^{3+}-\mathrm{O}\right)$ and $\left(\mathrm{Ni}^{2+}-\mathrm{O}\right)$ that takes place inside the tetrahedral sites, and the other absorption band is $\mathrm{v}_{2}$ Between $\left(300-450 \mathrm{~cm}^{-1}\right)$ this is linked to $\left(\mathrm{Fe}^{3+}-\mathrm{o}\right)$ and $\left(\mathrm{Ni}^{2+}-\mathrm{o}\right)$, which takes place into the octahedral sites. Absorption reaches a peak at $330 \mathrm{~cm}^{-1}$ and is represented by $v_{3}$, is assign to the oscillation of zinc atoms in the strength fields represented by their tetrahedral circumference [15]. 


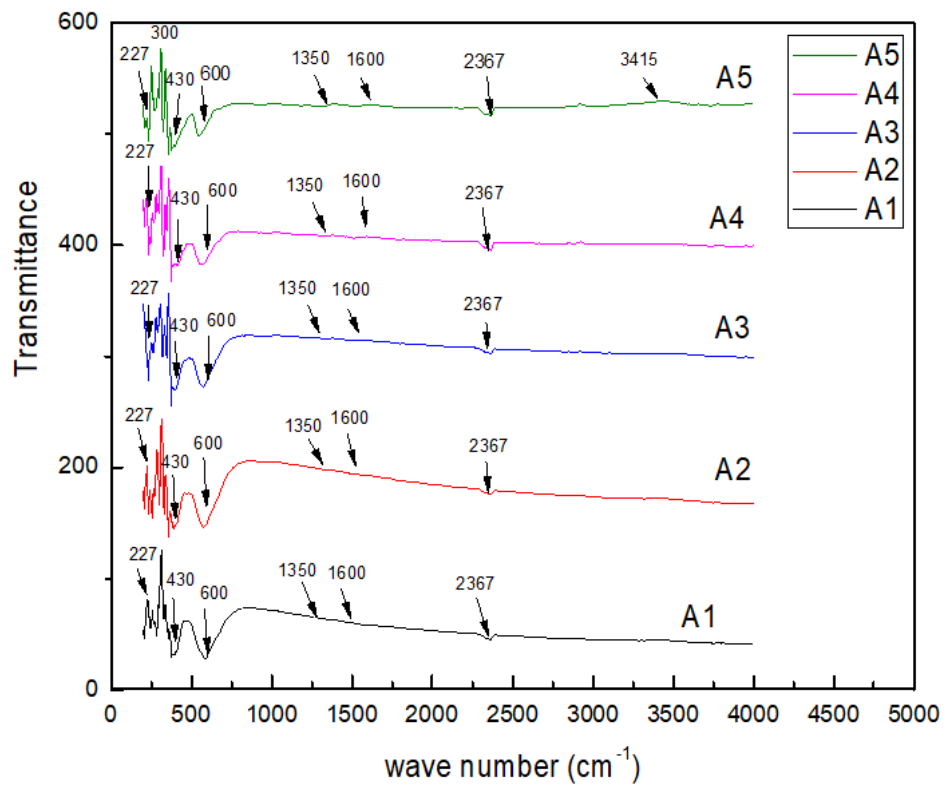

Figure 5. FTIR of samples prepared by sol gel combustion method

Fig. 5. represents the FTIR spectrum of the models arranged by chemical precipitation method. It showed that the natural vibratory position of the tetrahedral group is greater compared to the octahedral group, and the reason for this is that the octahedral group has a longer band length whereas the tetrahedral group has a shorter band length. According to the engineering application of ferrite, metal cations are located near oxygen ions in two different sub-lattices of ferrite. The FTIR spectra of the $\mathrm{Ni}_{(1-\mathrm{x})} \mathrm{Zn}_{\mathrm{x}} \mathrm{Fe}_{2} \mathrm{O}_{4}$ indicate that two strong absorption bonds are at $\left(587-557 \mathrm{~cm}^{-1}\right)$ and $\left(383-363 \mathrm{~cm}^{-1}\right)$. These bonds $\left(v_{1}, v_{2}\right)$ were identified as a result of the oscillation of the oxygen-metal ion compounds at the tetrahedral and octahedral sites. Differences in bond sites $\left(v_{1}, v_{2}\right)$ arise due to the variation in the $\mathrm{Fe}^{3+}-\mathrm{O}^{2-}$ distance of tetrahedral and octahedral groups [16].

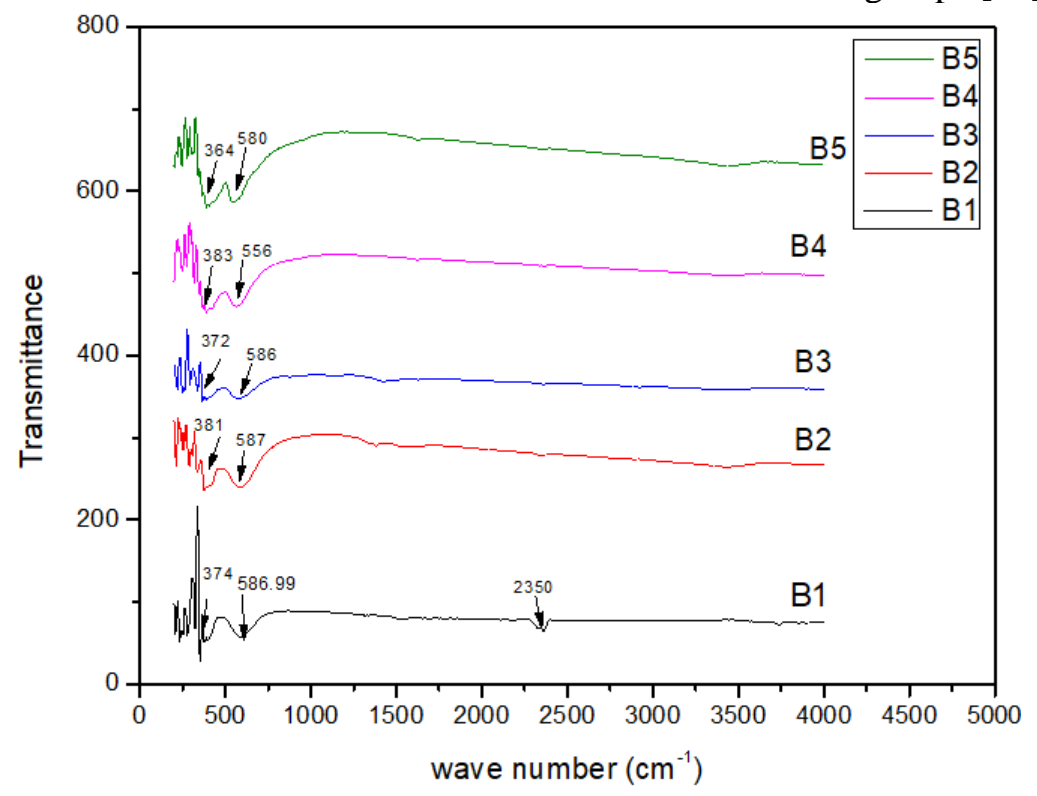

Figure 6. FTIR of samples prepared by common chemical precipitation method

\subsection{Electrical properties}

\section{Dielectric constant}

The dielectric constant is one of the most important electrical properties of materials. Where it based on regularity of the alternating electric field, the level of variation in the field time, the sintering temperature, the chemical composition, the defects of the materials, the method of preparation, the particle size. Figure $(7,8)$ shows that the insulator constant is high at low frequencies, gradually decreases with increasing frequency [17]. 
The difference in the Insulator fixed can be clarified on the base of the polarization created in the frequency response and the phenomenon of electronic exchange in ferritic materials. At low frequencies, the electronic interchange amongst $\mathrm{Fe}$ and $\mathrm{Fe}$ occurs at the location of the eight surfaces and toward the applied field. At low frequencies, there are four dissimilar sorts of polarization (electronic, ionic, dipole, spatial charge), but at high frequencies, the dielectric constant depends merely on ionic and electrical polarization, and this leads to a decrease in the overflow of polarity and thus the assessment of the dielectric fixed decreases.

The low in the Insulator constant with increasing frequency can be explained on the basis of the portable distance charge needs limited time to cross up to the applied alternating field and this leads to the field being applied at high frequencies being greater than the frequency of the electron exchange, and thus the electron exchange process produces a conflicting field. The direction of the field, and thus the electrons rotate around themselves, in a periodic motion. This reduces the probability that the electrons will reach the granular boundaries, and this polarization decreases and thus leads to a decrease in the dielectric fixed with rising frequency [18][19].

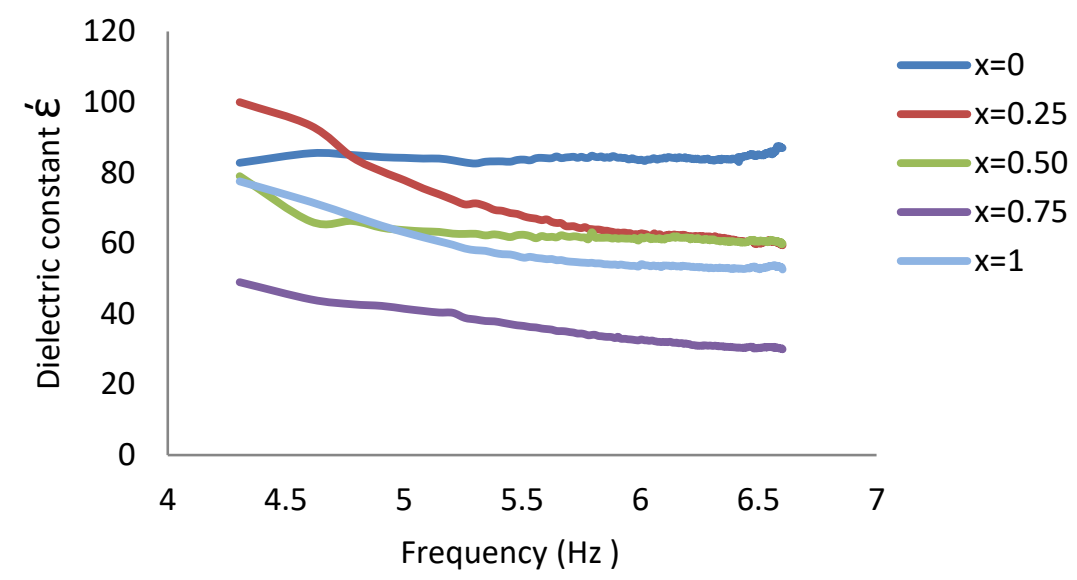

Figure 7. Frequency dependence of dielectric fixed for samples arranged by sol-gel auto combustion

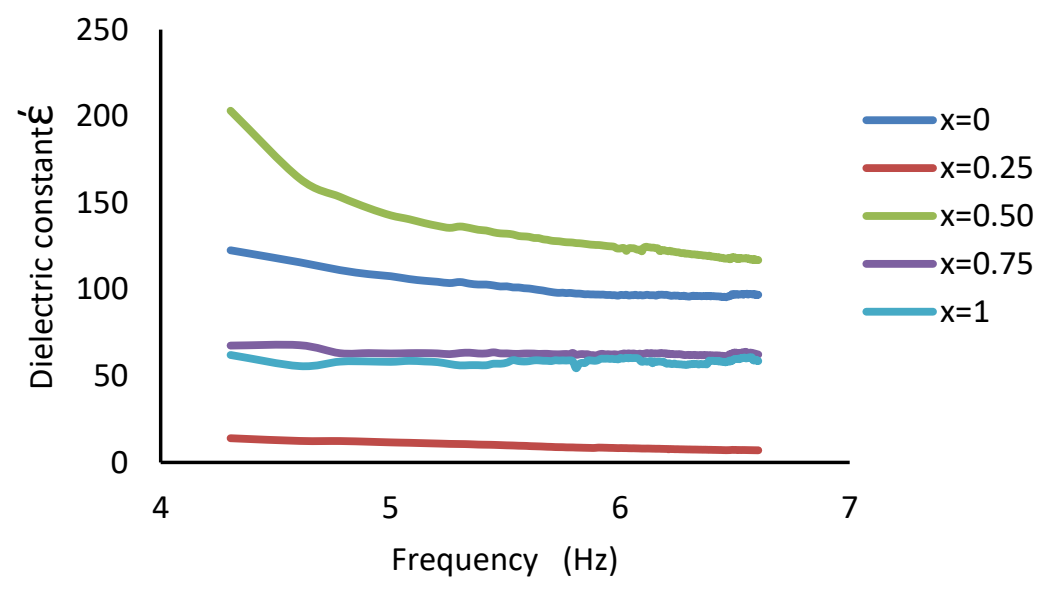

Figure 7. Frequency reliance of dielectric fixed for samples prepared by co-precipitation method

\section{Dielectric loss factor}

Dielectric loss factor is immediately proportional to the energy dispersion in the sequestration material, and for this the knowledge of the value of dielectric loss factor is of immense substantial in many uses of ferrite materials in order to know the ultimate functioning frequency in magnetic resources. Figure $(9,10)$ shows the appearance of almost identical behavior in all models where the values of the loss coefficient are large at low frequencies and decrease with increasing regularity of the projected electric field. This decrease can be clarified by using the following relationship: 


$$
\varepsilon^{\prime \prime}{ }_{r}=\frac{d}{2 \pi R_{p} \varepsilon_{0} A f} \ldots .(1-1)
$$

through the relationship (1-1) it is pleasant that the dielectric loss factor is inversely proportional to the frequency and that the increase in frequency leads to overcoming the decrease in the resistance [20].

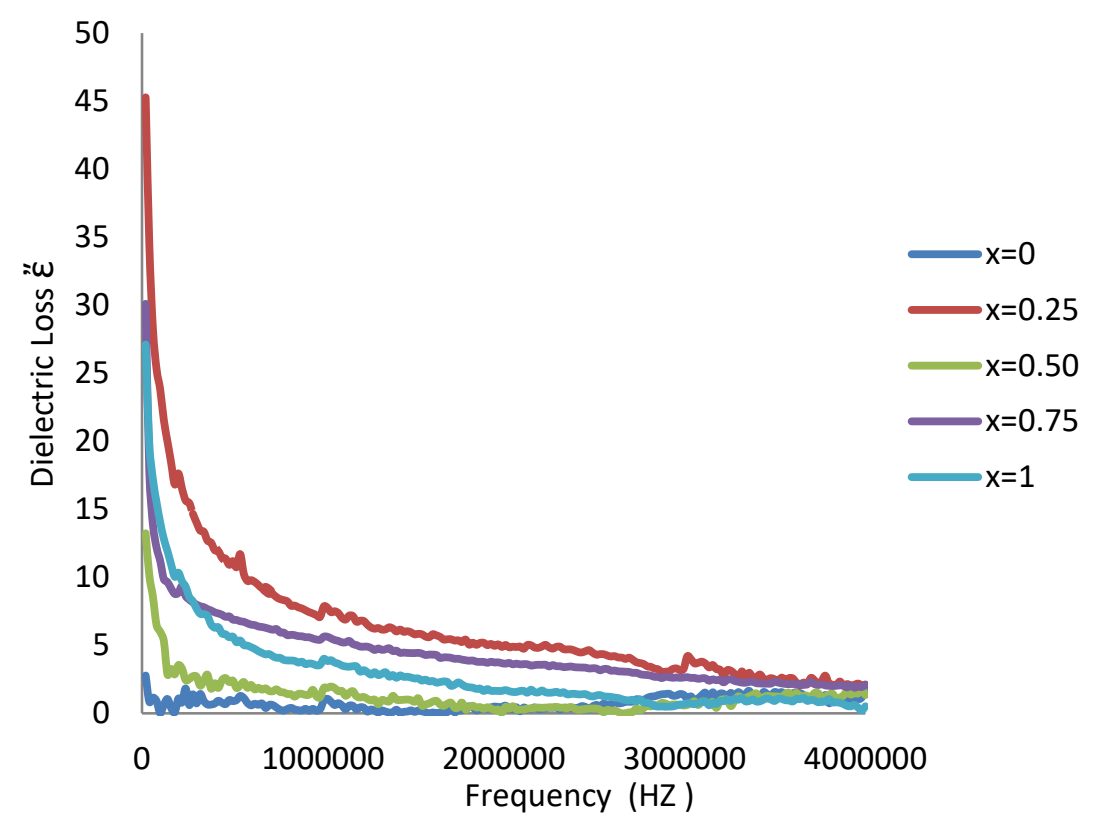

Figure 9. Plot of dielectric loss factor with frequency for samples arranged by sol-gel auto combustion

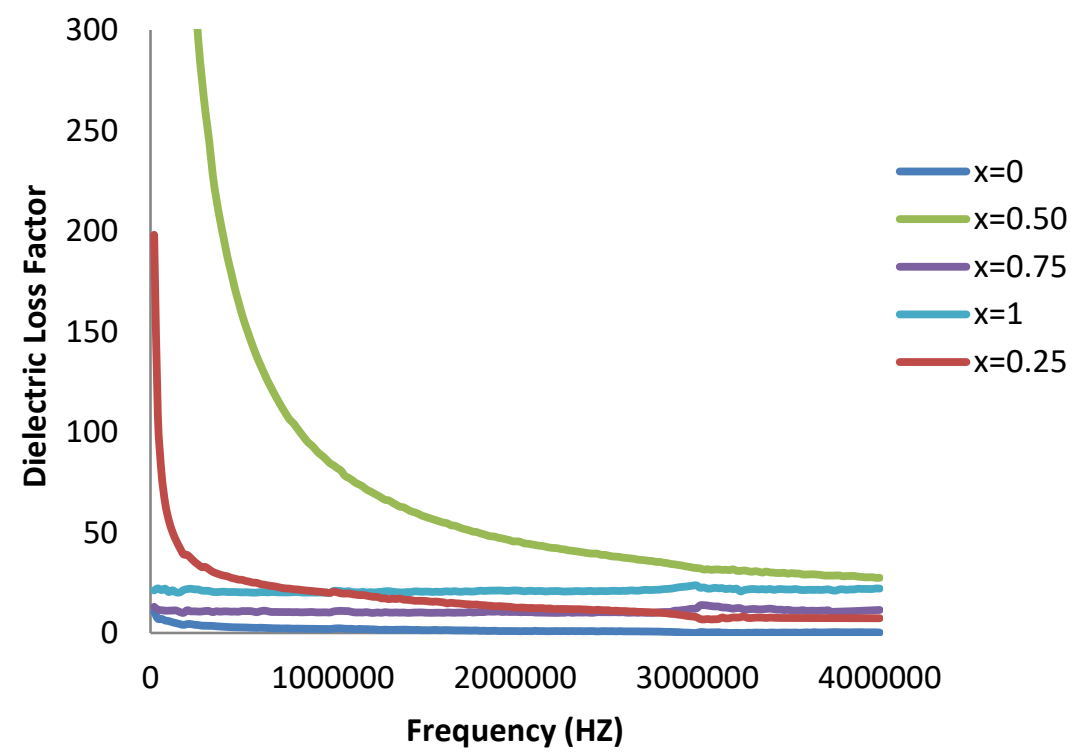

Figure 8. plot of Insulator loss factor with frequency for sample prepared by co-precipitation method

\section{Conclusion}

$\mathrm{Ni}-\mathrm{Zn}$ ferrite and common formula $\mathrm{Ni}_{(1-\mathrm{x})} \mathrm{Zn}_{\mathrm{x}} \mathrm{Fe}_{2} \mathrm{O}_{4}$ where $\mathrm{X}=0,0.25,0.50,0.75$ and 1 were prepared by solgel auto combustion and co-precipitation methods. The existence of $\mathrm{Zn}^{+2}$ ions reason a significant variation in electrical and structural of the properties. The x-rd results reveal spinel cubic structure for all samples. The lattice fixed (a) rises with the $\mathrm{Zn}$ content from 8.327 to $8.432 \AA$ for sol-gel auto combustion method and from 8.332 to $8.450 \AA$ for co-precipitation method. Crystalline size is determined from the highest peak (331) using the Scherrer's equation. The crystalline size goes down with the zinc content. FTIR study shows the cationic 
exchange between the site A and the site B. Electrical properties showed that the dielectric fixed with all specimens go down with rise frequency.

\section{References}

[1] M. A. Dar, K M. Batoo, V. Verma, W. A. Siddiqui and R. K. Kotnala, "Synthesis and characterization of nano-sized pure and Al-doped lithium ferrite having high value of dielectric constant," Journal of Alloys and Compounds, pp. 493:553, 2010.

[2] V. R. Kulkarani, M. M. Todhar and A. S. Vaingankar, "Electrical Resistivity \& Cation Distribution in $\mathrm{Cu}_{\mathrm{x}} \mathrm{Cd}_{1}$ Minus $\mathrm{Fe}_{2} \mathrm{O}_{4}$ System," Indian Journal of Pure and Applied Physics, vol. 24, pp. 294, 1986.

[3] N. Rezlesus and E. Rezlesus, "Dielectric Properties of Copper Containing Ferrites," Physica Status Solidi, vol. 23, no. 2, pp. 575-582, 1974.

[4] R. Peelamedu, C. Grimes, D. Agrawal, R. Roy, "Ultralow dielectric constant nickel-zink ferrites using microwave sintering,” Journal of Materials Research, vol. 18, pp. 2292-2295, 2003.

[5] R. Valenzuela, Magnetic Ceramices. Cambridge: Cambridge University Press, 1994.

[6] V.R.K. Murthy, "Electrical conductivity of some nickel-zinc ferrites," Phys. Status Solidi, vol. 38, no. 2, pp. 647-651, 1976.

[7] R. Hochschild, H. Fuess, J. Mater. Chem. 10 vol. 539, 2010.

[8] J. Smit, H.P.J. Wijn, Ferrites: Philips Technical Library, Eindhoven, The Netherlands, pp.157-158, 1959.

[9] J. Smit, H.P.J. Wijn, Ferrites: Physical Properties of Ferrimagnatic Oxides in Relation to their Technical Applications, N.V. Philip's Gloeilampenfabrieken, Eindhoven, The Netherlands, pp. 136-176, 1959.

[10] C.N. Chinnasamy, A. Narayanasamy, N. Ponpandian, "Mixed spinel structure in nanocrystalline NiFe2O4," Physical Review B, vol. 63, no. 18, pp. 184108, 2001.

[11] M. Atif, S.K. Hasanain, M. Nadeem, "Magnetization of sol-gel prepared zink ferrite nanoparticles: effects of inversion and particle size," Solid State Commun., vol. 138, no. 8, pp. 416-421, 2006.

[12] S.M.Rathod ,"Synthesis and characterization of Nano crystalline Ni-Cu-ZnFerrite prepared by Sol-gel auto combustion method," International Journal of Advancements in Research and Technology, vol. 6, no. 1, pp. 2278-7763, 2012.

[13] K.R. Krisha,"Structural and Electrical conductivity studies in Nickel-Zinc Ferrite," Advances in Materials Physics and chemistry, pp. 185-191,2 012.

[14] M.Abdullah Dar, "Study of structure and magnetic properties of Ni-Zn ferrite nano-particles synthesized via co-precipitation and reverse micro-emulsion technique,"AppI Nano sci, 2014.

[15] F. Shahbaz Tehrani, V. Daadmehr, A. T. Rezakhani b, R. Hosseini Akbarnejad, S. Gholipour," Structural,magnetic, and optical properties of zinc- and copper- substituted nickel ferrite nanocrystals," Journal of Superconductivity and Novel Magnetism, vol. 25, pp. 2443-2455, 2012.

[16] Sadaf Bashir Khan, Syed Irfan, Shern-Long Lee, "Influence of $\mathrm{Zn}^{+2}$ Doping on Ni-Based Nanoferrites; $\left(\mathrm{Ni}_{1-\mathrm{x}} \mathrm{Zn}_{\mathrm{x}} \mathrm{Fe}_{2} \mathrm{O}_{4}\right)$ ", Nanomaterials (Basel)., vol. 9, no.7, 2019.

[17] M.N. Ashiq, "Effect on physical, Electrical and Magnetic properties of strontium Hex ferrite Nanomaterial Doped with Binary Mixtures of various Metal Ions ",ph.D,University Istamabed ,4$14,(2009)$.

[18] V. P. Singh, G. Kumar, P. Dhiman, R. K. Kotnala, J. Shah, Kh. M. Batoo and M. Singh, "Structural, dielectric and magnetic properties of nanocrystalline $\mathrm{BaFe}_{12} \mathrm{O}_{19}$ hexaferrite processed via sol-gel technique", J. Adv. Mat. Lett.,vol. 5, pp. 447-452, 2014. 
[19] I. Sadiq, I. Ali, E. V. Rebrov, Sh. Naseem, M. N. Ashiq, and M. U. Rana, "Influence of Nd-Co Substitution on Structural, Electrical, and Dielectric Properties of X-Type Hexagonal Nanoferrites", JMEPEG, vol. 23, pp.622-627, 2014.

[20] A. M., Mohammad, S. M. A. Ridha,, T . H. Mubarak, "Dielectric properties of Cr-Substituted Cobalt Ferrite Nanoparticles Synthesis by Citrate-Gel Auto Combustion Method," International Journal of Applied Engineering Research, vol. 13, no. 8, pp. 6026-6035, 2018. 